\title{
V238AC: nueva variedad de maíz de grano amarillo QPM
}

\author{
Bulmaro Coutiño Estrada ${ }^{1 \S}$ \\ Gricelda Vázquez Carrillo² \\ ${ }^{1}$ Campo Experimental Centro de Chiapas-INIFAP. Carretera Ocozocoautla-Cintalapa km 3, Ocozocoautla, \\ Chiapas. CP. 29140. Tel. 01(800) 0882222, ext. 86306. ${ }^{2}$ Campo Experimental Valle de México-INIFAP. \\ Carretera Los Reyes-Texcoco km 13.5, Coatlinchán, Texcoco, Estado de México. Tel. 01(800) 0882222, \\ ext. 85364. (vazquez.gricelda@inifap.gob.mx). \\ ${ }^{\S}$ Autor para correspondencia: coutino.bulmaro@inifap.gob.mx.
}

\section{Resumen}

Los productores de la región de la Meseta Comiteca, Chiapas, pertenecen a la etnia Tojolabal y se caracterizan por tener índices muy altos de desnutrición, cultivan más de 82000 ha de maíz, utilizando variedades criollas de la raza Comiteco, con un rendimiento promedio de $1.7 \mathrm{t} \mathrm{ha}^{-1}$, por lo que se requiere de una variedad mejorada con mayor calidad nutritiva. En el año 2002 se inició un esquema de mejoramiento genético por retrocruzas en el Sintético A, proveniente de un compuesto de 17 variedades criollas de la raza Comiteco de grano amarillo, con objeto de incorporarle el gene opaco-2, utilizando como donante la línea CML-172. Después de dos retrocruzas se formó un compuesto con las mejores líneas con más de $50 \%$ de lisina y triptofano y se le registró en el SNICS con la denominación V238AC. Esta nueva variedad puede producir de 5 a $7 \mathrm{t} \mathrm{ha}^{-1}$ en la Meseta Comiteca, con altitudes de 1500 a $1800 \mathrm{~m}$, con más de $600 \mathrm{~mm}$ de precipitación pluvial.

Palabras clave: Zea mays L., maíz QPM V238AC, raza Comiteco, retrocruzas en maíz.

Recibido: abril de 2018

Aceptado: julio de 2018 
Durante 2015, en la región de la Meseta Comiteca, Chiapas, se cultivaron 82276 ha de maíz y se produjeron 144597 t de grano, que equivalen a 13.5\% de la producción total estatal (SIAP, 2017). Las variedades cultivadas son exclusivamente criollas, de la raza Olotón, principalmente (Perales et al., 2005) con rendimientos de $1.7 \mathrm{t} \mathrm{ha}^{-1}$. Los productores pertenecen a las etnias Tzeltal y Tzotzil y se caracterizan por tener índices muy altos de desnutrición (INEGI, 2017), ya que su dieta alimenticia está basada en el consumo del grano de maíz en sus múltiples formas alimenticias como tortillas, pozol, atoles, elotes, tamales, etc. La desventaja del maíz es su bajo contenido de proteína, alrededor de $9 \%$ y el bajo contenido de aminoácidos lisina y triptofano, los cuales son considerados como esenciales para un buen desarrollo corporal y mental, sobre todo de los infantes.

En la década de los años 60's, fue descubierto en la Universidad de Purdue, Indiana, USA, un gene mutante recesivo en el maíz denominado opaco-2, el cual incrementa en casi el doble la cantidad de los aminoácidos lisina y triptofano (Mertz et al., 1964), este gene fue incorporado a muchos maíces, pero su uso comercial tuvo muchos problemas debido a la consistencia suave o harinosa del endospermo, lo que causaba bajo peso del grano y susceptibilidad a las plagas de campo y de almacén, por lo que la investigación sobre este gene declinó. El Centro Internacional de Mejoramiento de Maíz y Trigo (CIMMYT) continuó trabajando en pequeña escala y en 1992 logró cambiar la textura harinosa del endospermo con la inclusión de genes modificadores, los cuales le dieron a los maíces opaco-2 una textura más dura, muy semejante al de un maíz normal, sin cambiar su calidad de proteína, por lo que estos nuevos maíces fueron llamados Quality Protein Maize (QPM) en sustitución de la designación opaco-2 (Vasal et al., 1980).

Así como en la tortilla, en otros productos alimenticios como frituras y elotes también se mantiene el valor proteínico, inclusive, el elote de maíz QPM contiene cantidades significativamente superiores de lisina y triptofano en comparación al maíz normal (Ortega et $a l ., 1991)$. Scheuch y Francis (1975) presentan varios métodos de conversión para incorporar el gene opaco-2 a los maíces normales y recomiendan que los programas de extensión y desarrollo integral incluyan en sus objetivos el mejoramiento de la nutrición humana a base de un maíz de alta calidad de proteína.

Con estos antecedentes, se inició un trabajo de mejoramiento genético por medio de retrocruzas para ofrecerles a los habitantes del medio rural nuevas variedades mejoradas con mayor calidad nutritiva. La conversión se inició utilizando la variedad sintético-A, proveniente de dos ciclos de selección de familias de medios hermanos realizadas en la población Comiteca Amarilla, como progenitor recurrente y como donante del gene opaco-2 se utilizó la línea CML-172 del CIMMYT. En 2002 se obtuvo la F1 y en 2003 se hicieron autofecundaciones para obtener líneas S1, con más del 61 y $67 \%$ de lisina y triptofano. En 2004, se sembraron estas líneas S1 de la F2 para hacer la primera retrocruza (RC1) hacia el progenitor Comiteco amarillo. En 2005 se sembraron las RC1 y se autofecundaron las plantas con fenotipo de Comiteco para obtener la F2, de cada línea fueron seleccionados visualmente los granos segregantes con $25 \%$ de opacidad y se determinó su contenido de aminoácidos para seleccionar un grupo de 21 líneas con más de 50\% de aminoácidos, respecto al testigo de grano normal.

En 2006 se realizó la segunda retrocruza (RC2) utilizando estas 21 mejores líneas con más de 50\% de lisina y de triptofano, las cuales fueron cruzadas con el progenitor Comiteco amarillo. En 2007 se sembraron las retrocruzas y se autofecundaron plantas con el fenotipo de Comiteco para obtener la F2 de la RC2, estas autofecundaciones se les determinó el contenido de lisina y triptofano y con 
las de mayor calidad de proteína se hizo un compuesto mecánico para obtener la semilla original de la variedad "Comiteco amarillo QPM", la cual tiene $87.5 \%$ de germoplasma de Comiteco y $12.5 \%$ del donante QPM.

Con esta semilla, en 2011 se sembraron 15 parcelas de evaluación con productores del municipio de Comitán, obteniendo un rendimiento promedio de $5.29 \mathrm{t} \mathrm{ha}^{-1}$ y superando de 5 a $7 \%$ a los testigos criollos de 2012 a 2016 se probó con productores de Comitán, La Trinitaria y Las Margaritas, obteniendo un rendimiento promedio de $5.318 \mathrm{t} \mathrm{ha}^{-1}$. En marzo de 2015 se le registró en el Catálogo Nacional de Variedades de Plantas del Servicio Nacional de Inspección y Certificación de Semillas de la SAGARPA, con el nombre de V238AC con el número de registro MAZ-1612-050315. El título de obtentor se encuentra en trámite ante la misma dependencia.

Las plantas de la variedad de maíz V238AC llegan a crecer $2.5 \mathrm{~m}$ y la mazorca se inserta a $1.45 \mathrm{~m}$, inician la liberación de polen a los 101 días, llegan a elote a los 135 días, los cuales son muy dulces de $13.5^{\circ}$ Brix, y se puede cosechar el grano a los 200 días. Es muy parecida a las variedades criollas, pero su valor agregado es que el grano de color amarillo contiene aminoácidos esenciales que la hacen más nutritiva que un maíz normal. Las mazorcas son de forma cónica-cilíndrica, de $20 \mathrm{~cm}$ de largo y de $4 \mathrm{~cm}$ de diámetro, tienen de 12 a 16 hileras de grano y cada hilera puede tener de 40 a 45 granos (Figura 1). Los granos son de endospermo color amarillo y de textura intermedia, entre semicristalina y semidentada, contienen $12.1 \%$ de proteína, que los hacen más nutritivos que los granos de otras variedades, pero lo que le da mayor valor nutritivo es que contienen de 50 a $60 \%$ más de los aminoácidos esenciales lisina y triptofano.

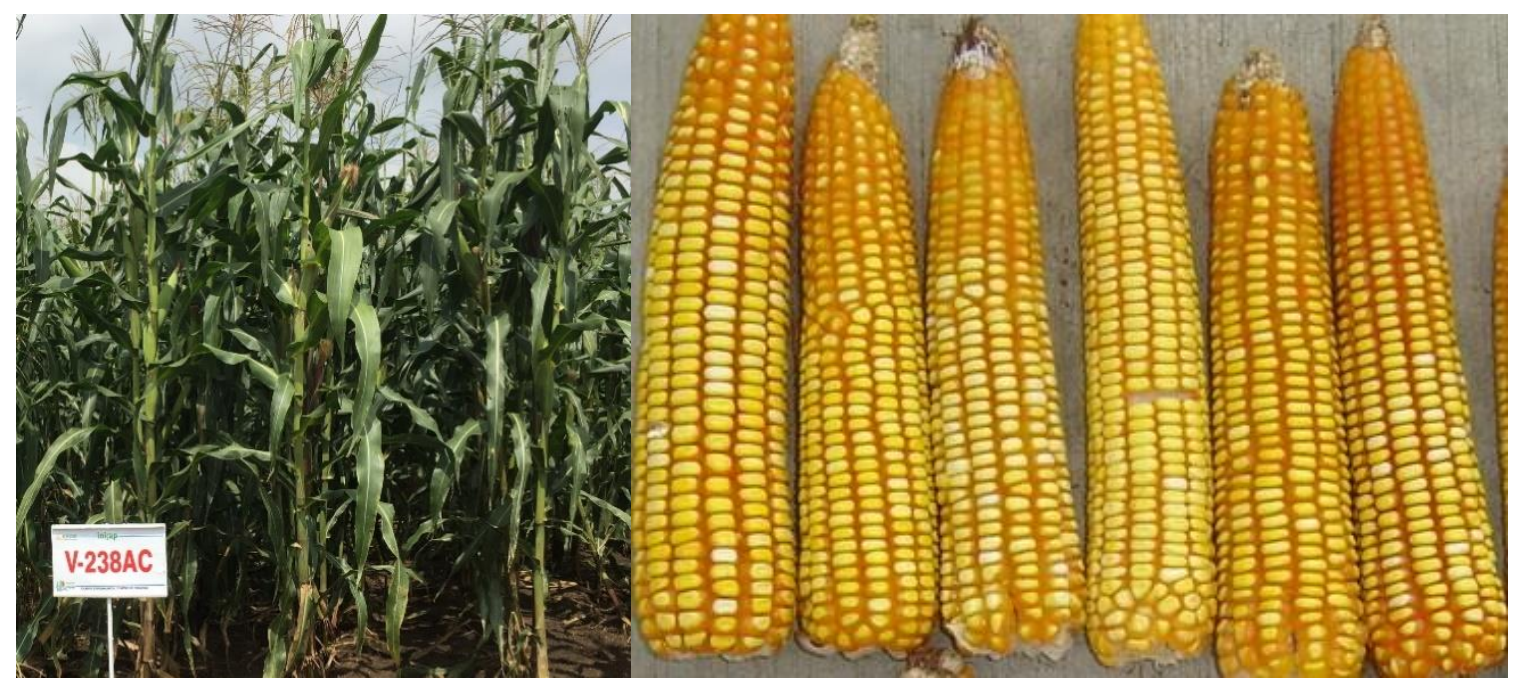

Figura 1. Aspecto de planta en estado de elote y de mazorcas de la V238AC.

Su peso hectolítrico es de $76.9 \mathrm{~kg}$ hl, con granos de primera calidad para la elaboración de tortillas. Por cada kg de grano nixtamalizado se produce $1.71 \mathrm{~kg}$ de masa y $1.4 \mathrm{~kg}$ de tortilla, las cuales son de agradable color amarillento y buena calidad. Puede cultivarse en los Distritos de Desarrollo Rural de San Cristóbal de Las Casas y de Comitán, en los municipios de Amatenango, Teopisca, Las Rosas, Huixtán, Comitán, Las Margaritas, La Trinitaria, La Independencia, Tzimol, de clima A(C)w, semicálido subhúmedo, y otras similares a altitudes de 1200 a 1800 m y precipitaciones de $800 \mathrm{~mm}$, tanto en siembras de pul-jhá (echar agua, del Tojolabal) como de temporal. 
Como es un gene recesivo el que confiere el mayor valor nutritivo del grano, si se polinizan las flores femeninas por un maíz normal, no se obtendrá dicho valor nutritivo, por lo que el aislamiento de los lotes de producción de semilla y de grano debe ser muy estricto.

\section{Conclusiones}

Para mantener la pureza genética y para la producción de semilla certificada se sugiere sembrar a densidades de población de 50000 plantas $\mathrm{ha}^{-1}$, siguiendo las recomendaciones del SNICS de aislamiento por espacio o tiempo y haciendo los desmezcles adecuados. En el Campo Experimental Centro de Chiapas se produce semilla en categoría registrada para las empresas semilleras que estén interesadas en la producción y comercialización de la categoría certificada.

\section{Agradecimientos}

Se agradece al Fomix-Chiapas por el financiamiento del Proyecto: Introducción del gene opaco-2 modificado a los maíces criollos Olotón y Comiteco para incrementar su calidad de proteína, durante los años 2004 a 2007. También se agradece el apoyo de campo brindado por el MC Grisel Sánchez Grajalez y el Ing. David Rincón Espinosa.

\section{Literatura citada}

Coutiño, E. B. 1993. Normas y técnicas para producir semilla certificada de variedades de maíz. Folleto técnico No. 7. Instituto Nacional de Investigaciones Forestales, Agrícolas y Pecuarias (INIFAP). Campo Experimental Centro de Chiapas. Ocozocoautla, Chiapas, México. 33 p.

INEGI. 2017. XII Censo general de población y vivienda. Regiones pobres del estado de Chiapas. Microregiones de Chiapas. www.inegi.gob.mx.

Mertz, E. T.; Bates, L. S. and Nelson, O. F. 1964. Mutant gene that changes protein composition and increases lysine content of maize endosperm. Science. 145:279-280.

Ortega, E. I.; Villegas, E.; Bjarnason, M. and Short, K. 1991. Changes in dry matter and protein fractions during kernel development of quality protein maize. Cereal Chem. 68(6):482-486.

Perales, H. R.; Benz, B. F. and Brush, S. 2005. Maize diversity and ethnolinguistic diversity in Chiapas, Mexico. Proc. Natl. Acad. Sci. 102(3):949-954.

Scheuch, F. y Francis, A. C. 1975. Sistemas rápidos para aumentar la calidad proteínica del maíz harinoso con el gene opaco-2. In: maíz de alta calidad proteínica. Compendio de las ponencias presentadas en el simposio internacional Cimmyt-Purdue. Ed. Limusa, SA.109-126 pp.

SIAP. 2017. SAGARPA. Anuario estadístico de la producción de maíz en el estado de Chiapas. Ciclo agrícola 2015. www.siap.sagarpa.gob.mx.

Vasal, S. K; Villegas, E.; Bjarnason, M.; Gelaw, B. and Goertz P. 1980. Genetic modifiers and breeding strategies in developing hard endosperm opaque-2 materials. In: improvement of quality traits of maize for grain and silage use. Pollmer, W. G. and Phipps, R. H. (Eds.). The Hague, The Netherlands. 37-73 pp. 